\title{
EVALUATION OF SOME RICE VARIETIES FOR THEIR ABILITIES TO IMMATURE EMBRYO CULTURE UNDER SALINITY STRESS

\author{
Abd El-Maksoud, M.M. ${ }^{1}$; A.E. Draz ${ }^{2}$ and Sara A. El-Leithy ${ }^{2}$ \\ 1- Genetic Dept. Faculty of Agric., Mansoura Univ., Mansoura, Egypt. \\ 2- Rice Res. and Training Center (RRTC), Sakha, Kafr El-Sheikh, Egypt.
}

\begin{abstract}
This study was carried out to evaluate some rice varieties for their ability to immature embryo culture under salt stress condition. Therefore, three varieties were used as the donor plants for immature embryo culture in order to assessment their abilities for response under salinity stress. The recorded data on the embryo response percentage, shoot bud percentage and plantlet percentage were subjected for statistical analyses. The test of significance of the mean squares of genotypes at the three levels of $\mathrm{NaCl}$ except for embryo response percentage at control level, indicated the presence of significant differences among these genotypes for all in vitro traits. This finding indicated that these genotypes were varied in their response to immature embryo culture. Furthermore, levels and genotype $\times$ levels interaction mean squares were highly significant in plantlet percentage trait. This result indicated that these genotypes gave different response for different $\mathrm{NaCl}$ levels. At level 2000 ppm, although the greatest mean values for shoot bud percentage was recorded in Giza 177 with the mean of $69.98 \%$ which was not significantly differed than Giza 182 $(64.00 \%)$. Also, the greatest mean values for plantlet percentage was recorded in Giza 182 with the mean of $58.79 \%$. On the other hand, the lowest shoot bud percentage was observed in Giza 178 with the mean of $44.80 \%$ as well as, Giza 177 which recorded the lowest values for plantlet percentage with the mean of $34.58 \%$. Regarding the third level of $\mathrm{NaCl} 4000$ ppm, the best variety with the highest mean values for shoot bud and plantlet percentages was Giza182. This finding indicated that Giza 182 was highly tolerant to $\mathrm{NaCl}$ concentration at in vitro levels and may produce somaclones with $\mathrm{NaCl}$ tolerance genes.
\end{abstract}

\section{INTRODUCTION}

Rice is highly sensitive to salinity; since its sensitivity is affected by the growth stage, concentration of salts, the period of salinization, humidity and solar radiation. Rice yields decrease with increasing the salinity. The rate of decrease in yield is approximately $13 \%$ for each unit increase in salinity (Hebbara et al., 1992). Therefore, plant breeder take their attention to develop salt-tolerant crops by genetic approaches (Munns, 2005). Flowers and Yeo (1995) suggested five possible ways, which were appropriate at that time, to develop salt tolerant crops: (1) develop halophytes as alternative crops; (2) use inter-specific hybridization to raise the tolerance of current crops; (3) use the variation already present in existing crops; (4) generate variation within existing crops by using recurrent selection, mutagenesis or tissue culture, and (5) breed for yield rather than tolerance. These all remain possible solutions to the problem.

Tissue-cultured cell lines could be used as a tool to in vitro selection for resistance to various stresses. Selection is done by placing a stress causing agent in tissue cultures containing dividing cells. Tissue culture techniques have been widely used for breeding purposes, especially in 
selection for stress tolerance. In the same time, tissue culture is a source of genetic variability that gives rise through genetic modifications during the process of in vitro culture to a phenomenon called somaclonal variation. The possible causes of somaclonal variation include chromosome aberrations, DNA amplification, and the occurrence of transposable elements. Further information, however, is needed about its precise nature, especially in rice, since recent works demonstrated that tissue culture techniques could be successfully used in the improvement of these species for tolerance to salinity (Zhang et al. 1995, Winicov 1996, Lutts et al. 1999) or other abiotic stresses (Adkins et al. 1995, Bertin et al. 1996). Thus, this investigation aimed to evaluate some rice varieties for their ability to immature embryo culture under salt stress condition, subsequently, the derived plants as somaclons could be evaluated for their behavior under field condition with respect to the important traits.

\section{MATERIALS AND METHODS}

In this investigation, three Egyptian rice varieties belong to the species (Oryza sativa, L.) were used. These varieties were: Giza 177,Giza178 and Giza 182. Two out of them (Giza 177 and Giza 182) were sensitive and the other variety (Giza 178) was tolerate. This investigation was carried out at the Biotechnology Lab of Rice Research and Training Center (RRTC), Sakha, Kafer El-sheikh, Egypt. During 2005 growing season, the three varieties were cultivated and all the agriculture preparation and fertilization were practiced as recommended for rice cultivation.

The general procedure of immature embryo culture technique was made as follow:

Panicles from each variety were collected at the suitable stage for immature embryo culture (Sarma and Devi, 1999). This stage could be determined as the morphology of spikelet, when the seed in soft dough stage formed 15-20 days after pollination.

Immature seeds were dehusked and surface - sterilized with $95 \%$ ethyl alcohol for one minute. Then, the seeds were rinsed one time with double sterilized distelled water. Subsequently, sterilization using mercuric chloride $\left(\mathrm{HgCl}_{2}\right)$ 1\% (W/V) solution with 2-3 drops per liter of Tween - 20 for 20 minutes were made. Seeds were rinsed three times with double sterilized distilled water. These immature seeds were pot in Petri dishes with sterilized filter paper to isolate the immature embryo by stress on it using sterilized forceps and cutter.

About 20 embryos were cultured in sterilized Petri dish $(60 \times 15 \mathrm{~mm})$ with induction medium (modified MS medium for embryo culture) according to Murashige and Skoog, (1962). The pH was adjusted to 5.8 before adding agar and autoclaving at $121 \mathrm{C}^{\circ}$ for 15 minutes. The responded embryos were recorded and the produced calli were transferred to regeneration medium which was supplemented with Zero, 2000 and $4000 \mathrm{ppm}$ of $\mathrm{NaCl}$ to study the ability of genotypes for their salt tolerance. Callus induced from each embryo was divided to three parts, each part was cultured in regeneration medium with two concentrations of $\mathrm{NaCl}$ in addition to the control. Then kept in a phytotron at 25-27 $\mathrm{C}^{\circ}$ with 16 hours light and 8 hours dark for 7 to 10 days. 
Shoot bud were recorded and transferred to MS medium free hormones. The regenerated plants with normal roots and shoots were carefully pulled up from test tubs and washed by tab water. These plantlets were transferred to the culture solution with the same concentration of $\mathrm{NaCl}$ for two weeks. The survived plantlets were gradually moved to normal conditions for further investigation.

The data were recorded on each replicate for the following traits:

- Embryo response percentage: This trait was determined as the ratio of the number of responded embryos (produced calli) to total number of embryos plated.

- Shoot bud percentage: This is the ratio of the number of shoot bud to the number of calli which were transferred to regeneration medium.

- Plantlet percentage: This is the ratio of the number of plantlet to the number of calli, which were transferred to regeneration medium.

In order to normalize the distribution of the percentage data which fall between 0.00 to 1.00 , these data were transformed by using arcsine $X^{1 / 2}$ function prior to statistical analyses for the in vitro studied traits which were responding immature embryos, shoot bud percentage and plantlet percentage. In the this study, different forms of analysis of variances were employed in order to test the significance of the differences between the genotypes in each concentration of $\mathrm{NaCl}$. In addition, a combined analyses of variance for genotypes over the $\mathrm{NaCl}$ levels was made for studied traits according to Steel and Torrie (1960).

\section{RESULTS AND DISCUSSION}

The preset study was conducted to study the in vitro genetic behavior of some genotypes of rice under salinity stress treatments. Analysis of variances for all studied in vitro traits are presented in Table 1. The test of significance on the mean squares of genotypes at the three levels of $\mathrm{NaCl}$ except for embryo response percentage at control level, indicated that there are significant differences among genotypes for all in vitro traits. This finding indicated that these genotypes varied in their response to immature embryo culture. However, replications mean squares were insignificant for all traits, indicating that there was no difference between spikes, which collected from each genotypes for immature embryo culture purpose. These results were agree with those obtained by Abd El-Maksaud, M.M. (1997) in wheat. In addition, the data which were obtained from the three $\mathrm{NaCl}$ for genotypes were set up in combined analysis of variance and the obtained results are presented in Table 2. Significant tests on the mean squares of genotypes were highly significant for all studied in vitro traits (shoot bud percentage and plantlet percentage). These finding indicated the presence of real differences among these genotypes with respect to the ability to regeneration. Therefore, the planned comparisons among these genotypes as well as the further partition of the phenotypic variance to its components are valied. These results were in agreement with those obtained by Seraj et al. (1997) and Aditya et al. (2004). Furthermore, levels and genotype x levels interaction mean squares were highly significant in plantlet percentage trait. This indicate that these genotypes gave different response at different $\mathrm{NaCl}$ 
levels. The same trend was observed in the previous investigation carried out by Lutts et al. (1998).

The mean performances of three genotypes for all studied in vitro traits at the three levels of $\mathrm{NaCl}$ are shown in Table 3. In general, the highest mean values for the studied traits at level 2000ppm and 4000ppm, indicated that these genotypes had a good tolerance to salinity stress at in vitro level. With regard to second level of $\mathrm{NaCl}(2000 \mathrm{ppm})$ the results in Table 3 revealed that the highest mean values for shoot bud percentage was recorded by Giza 177 (69.98\%) and not significantly differed than 182 $(64.00 \%)$. While, the highest mean values for plantlet percentage $(58.79 \%)$ was recorded by Giza 182 Variety. On the other hand, the lowest mean value for shoot bud percentage was $44.80 \%$ and recorded by Giza 178 variety as well as Giza 177 which recorded the lowest mean values for plantlet percentage (34.58\%). As shown in Table 3, it could be noticed that the highest mean values for shoot bud and plantlet percentage at 4000ppm of $\mathrm{NaCl}$ were recorded by Giza 182 variety since these values were $62.79 \%$ and $60.97 \%$, respectively. Regarding the third level of $\mathrm{NaCl} 4000 \mathrm{ppm}$, the best variety with the highest mean values for Shoot bud and plantlet percentages was observed in Giza182. Regarding the control treatment $(0.00 \mathrm{ppm} \mathrm{NaCl})$ the results in Table 3 showed that the highest mean values for shoot bud and plantlet percentage were $80.79 \%$ and $90.00 \%$, respectively and recorded by Giza 182 variety. While, this value was $60.29 \%$ for embryo response percentage trait and obtained by Giza 178 variety. On the other hand, the lowest mean values were $41.22 \%, 51.43 \%$ and $36.14 \%$ and recorded by Giza 182, Giza 178 and Giza 178, respectively. This finding indicated that Giza 182 was highly tolerant to $\mathrm{NaCl}$ concentration at in vitro levels and could be produce somaclones with $\mathrm{NaCl}$ tolerance genes.

Since, these genotypes investigated appeared different performance with different $\mathrm{NaCl}$ levels as observed for most studied in vitro traits. So, the combined data over the three $\mathrm{NaCl}$ levels could be more precise to present information concerning the in vitro behaviour of these varieties. Therefore, the means of three genotypes were combined from the data over the three levels of $\mathrm{NaCl}$ and the obtained results are shown in Table 3 . In spite of, non significant differences were observed among varieties for studied in vitro traits, Giza 177 and Giza 182 were the best for shoot bud percentage and plantlet percentage with means of 69.53 and 69.92 , respectively.

In general, the greatest overall values for embryo response was observed in Giza 178 and Giza 177 with means of 60.29 and 59.25, respectively. The variety Giza 182 was the best for plantlet percentage under all salinity stress. While the inferior variety for regeneration ability was Giza 178 for Shoot bud percentage and Giza 177 for plantlet regeneration percentage with respect to $\mathrm{NaCl}$ levels. These results are in agreement with the results obtained by Lutts et al. (1998).

The phenotypic variance among the three varieties for the studied in vitro traits was partitioned to its components; genotypic and environmental variances with respect to ANOVA of each level, in addition to genotypic, environmental and their interaction were determined from the ANOVA of the combined data. The obtained results in Table 4 revealed that both genotypic 
J. Agric. Sci. Mansoura Univ., 34 (9), September, 2009

9189 
Abd El-Maksoud, M.M. et al.

9190 
$\left(\sigma^{2} g\right)$ and environmental $\left(\sigma^{2} e\right)$ variances are positive while, the magnituded values of genotypic variances were higher then the corresponding values of environmental variance with respect to the studied traits at each levels except for plantlet percentage from the combined data. This finding indicated that these traits are mainly controled by genetic factors. However, in the case of plantlet percentage, the decrease in genotypic variance from the combined data may due to the increase of genotypic by environmental interaction variance. This may explain the fact that each genotype or a set of genotypes need altered media composition and/or culture conditions for responding to immature embryo culture as reported by Wang-HaiBo and Fan-YunLiu. (2006), Agrawal et al. (2006) and Al-Forkan et al. (2005). This result could be confirmed by the results of heritability estimates $\left(\mathrm{h}_{\mathrm{b}} \%\right)$, which were more than $50 \%$ for the studied traits except plantlet percentage from the combined data.

\section{REFERENCES}

Abd El- Maksoud, M-M- (1997): Genetic analysis of anther culture response in Egyption wheat (Triticum astivium L.). Agric Sci. Mansoura Univ., 22(1): 111-121.

Aditya, T-L; M-E, Hoque and M, Khalequzzaman. (2004): Response to high frequency callus induction ability from root regions of germinated embryo in indica rice. Pakistan-Journal-of-Biological-Sciences, 7(5): 861-864.

Al-Forkan,-M; M-A-, Rahim; T-, Chowdhury; P-, Akter and L-, Khaleda. (2005): Development of highly in vitro callogenesis and regeneration system for some salt tolerant rice (Oryza sativa L.) cultivars of Bangladesh. Biotechnology-,4(3): 230-234.

Adkins, S-W; R-, Kunanuvatchaidach and L-D-, Godwin. (1995):Somaclonal variation in rice drought tolerance and other agronomic characters. Aust. J. Bot, 43: 201-209.

Agrawal,-P-K; S-S-, Gosal and G-S-, Sidhu. (2006): Sequential reduction of 2,4-D improves whole plant regeneration from long-term maintained calli in some indica cultivars of rice. Oryza-; 43(1): 10-15

Bertin,-P; J-P, Busogoro; J-P, Tilquin; J-M, Kinet and J, Bouharmont. (1996): Field evaluation and selection of rice somaclonal variants at different altitudes. Plant-Breeding, 115(3): 183-188.

Flowers TJ and Yeo AR. (1995): Breeding for salinity resistance in crop Plants-where next? Australian Journal of Plant Physiology 22, 875884.

Hebbara,-M; D-P, Viswanath; A-, Naganagoud and B-, Basavaraj. (1992): Interrelationship between soil salinity and crop yields on vertisols. Journal of the Indian Society of Soil Science, 40(4): 888-889.

Lutts,-S; J-M, Kinet and J-, Bouharmont. (1998): $\mathrm{NaCl}$ impact on somaclonal variation exhibited by tissue culture-derived fertile plants of rice (Oryza sativa L.). Journal-of-Plant-Physiology, 152(1): 92-103. 
Abd El-Maksoud, M.M. et al.

Lutts,-S; J, Bouharmont and J-M, Kinet. (1999): Physiological characterisation of salt-resistant rice (Oryza sativa) somaclones.

Munns, R. (2005): Genes and salt tolerance: bringing them together. New Phytol. 167:645-663.

Australian-Journal-of-Botany, 47(6): 835-849.

Murashige, T. and F. Skoog (1962): A revised medium for rapid growth bioassays with tobacco tissue culture. Physiol. Plant. 15:473-497.

Sarma,-M-N and J-, Devi. (1999). Germination and growth of immature embryo in scented rice varieties. Oryza-,36(2): 165-166.

Seraj,-Z-I; Z-, Islam; M-O-, Faruque; T-, Devi and S-, Ahmed. (1997). Identification of the regeneration potential of embryo derived calluses from various indica rice varieties. Plant-Cell,-Tissue-and-OrganCulture, 48(1): 9-13.

Steel, R.G. and J.H. Torrie (1960): Principles and procedures of statistics. Mc-Graw Hill Book Company, INC. New York.

Wang-HaiBo and Fan-YunLiu (2006): Researching the mechanism in plant in vitro culture via "communication" experiment and to establish the methods widely used for tissue culture of wheat. Acta-AgronomicaSinica; 32(7): 964-971.

Winicov,-L (1996): Characterization of rice (Oryza sativa L.) plants regenerated from salt-tolerant cell lines. Plant Sciences, 133:105-111.

Zhang, G-Y; Y-,Guo; S-L-, Chen and S-Y, Chen. (1995): RFLP tagging of a salt tolerance gene in rice. Plant Science, 110: 227-234.

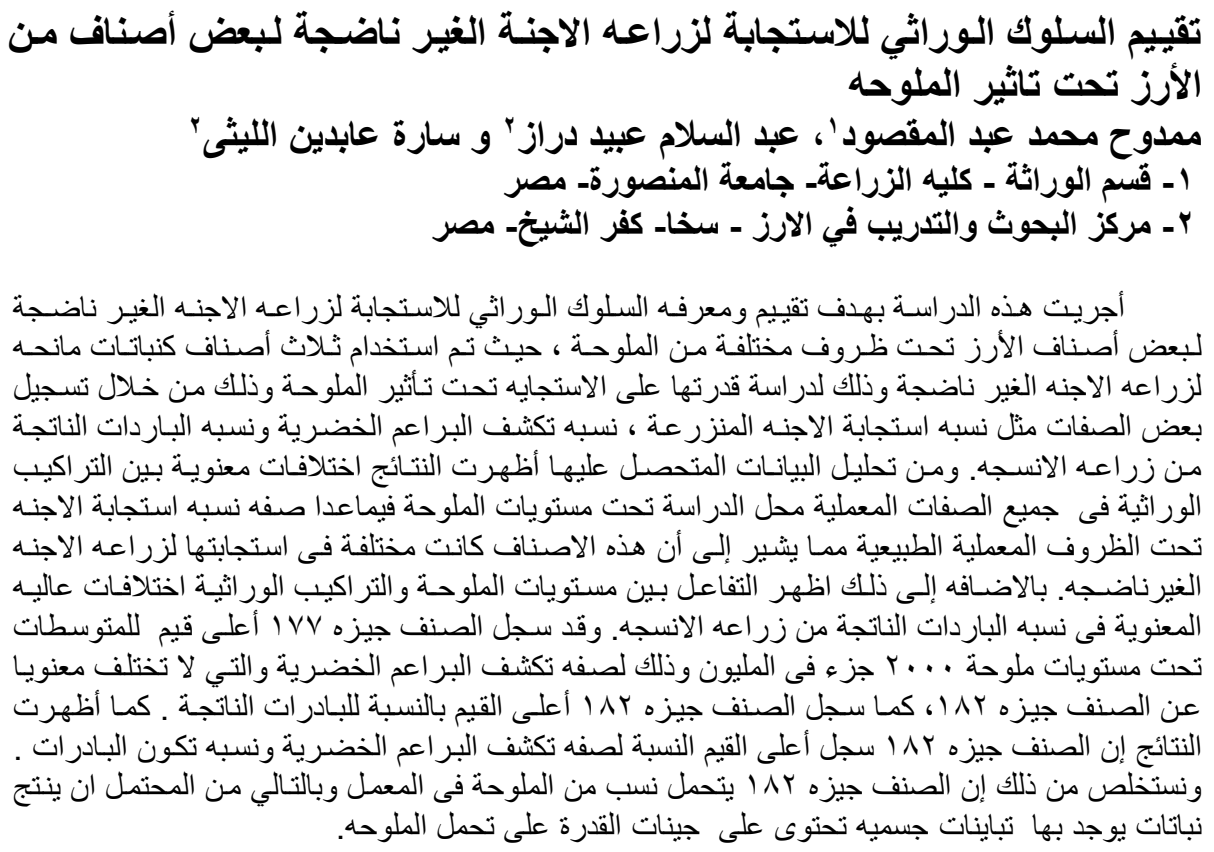


Table 1: Analysis of variances and the mean squares for in vitro traits for each $\mathrm{NaCl}$ concentration

\begin{tabular}{|l|c|c|c|c|c|c|c|c|c|c|}
\hline \multirow{2}{*}{ S.O.V } & \multirow{2}{*}{ d.f } & \multicolumn{4}{c|}{ Embryo response\% } & \multicolumn{3}{c|}{ Shoot bud \% } & \multicolumn{3}{c|}{ Plantlet\% } \\
\hline Replication & 3 & 47.75 & - & - & 267.36 & 53.84 & 66.61 & 144.69 & 23.154 & 18.52 \\
\hline Genotypes & 2 & $459.92^{* *}$ & - & - & $1020.24^{*}$ & $692.19^{*}$ & $215.61^{*}$ & $2925.04^{*}$ & $589.533^{* *}$ & $1358.18^{*}$ \\
\hline Error & 6 & 27.17 & - & - & 111.101 & 133.08 & 37.31 & 408.31 & 30.952 & 136.77 \\
\hline
\end{tabular}

${ }^{*}$ and ${ }^{* *}$, are significant at 0.05 and 0.01 levels of probability, respectively.

Table 2: Analysis of variances and the mean squares for the combined data over the three levels of NaCl regeneration ability traits

\begin{tabular}{|l|c|c|c|}
\hline S.O.V & d.f & Shoot bud\% & Plantlet\% \\
\hline Levels (NaCl) & 2 & 488.035 & $1489.965^{\star *}$ \\
\hline Reps./levels & 9 & 129.271 & 62.119 \\
\hline Genotypes & 2 & $1727.094^{\star *}$ & $2963.452^{\star *}$ \\
\hline Genotypes / levels & 4 & 100.473 & $954.648^{\star \star}$ \\
\hline Error & 18 & 93.830 & 192.010 \\
\hline
\end{tabular}

${ }^{*}$ and ${ }^{*}$, are significant at 0.05 and 0.01 levels of probability, respectively 
Table 3: The mean performances of three genotypes for in vitro traits under salinity stress and their combined

\begin{tabular}{|c|c|c|c|c|c|c|c|c|c|c|c|}
\hline \multirow[b]{2}{*}{ Genotypes } & \multicolumn{3}{|c|}{ Embryo response \% } & \multicolumn{4}{|c|}{ Shoot bud \% } & \multicolumn{4}{|c|}{ Plantlet \% } \\
\hline & Control & 2000 (ppm) & 4000(ppm) & Control & 2000(ppm) & 4000(ppm) & Comb. & Control & 2000(ppm) & 4000(ppm) & Comb. \\
\hline Giza 177 & $59.25 \mathrm{a}$ & - & - & $77 \mathrm{a}$ & $69.98 \mathrm{a}$ & $61.62 \mathrm{a}$ & $69.53 \mathrm{a}$ & $67.35 \mathrm{ab}$ & $34.58 \mathrm{~b}$ & $24.30 \mathrm{~b}$ & $42.07 \mathrm{a}$ \\
\hline Giza 182 & $41.22 \mathrm{~b}$ & - & - & $80.79 \mathrm{a}$ & $64.00 \mathrm{ab}$ & $62.79 \mathrm{a}$ & $69.19 \mathrm{a}$ & $90.00 \mathrm{a}$ & $58.79 \mathrm{a}$ & $60.97 \mathrm{a}$ & $69.92 \mathrm{a}$ \\
\hline Giza 178 & $60.29 \mathrm{a}$ & - & - & $51.43 \mathrm{~b}$ & $44.80 \mathrm{~b}$ & $49.53 \mathrm{~b}$ & $48.59 \mathrm{a}$ & $36.14 \mathrm{~b}$ & $48.20 \mathrm{ab}$ & $45.79 \mathrm{a}$ & $43.38 \mathrm{a}$ \\
\hline
\end{tabular}

Note: means followed by the same letter in the same column are not significantly differed.

Table 4: Genetic parameters for the studied in vitro traits at each level of salinity and the combined data over the two levels

\begin{tabular}{|c|c|c|c|c|c|c|c|c|c|c|c|c|}
\hline \multirow{2}{*}{$\begin{array}{c}\text { Genetic } \\
\text { parameters }\end{array}$} & \multicolumn{4}{|c|}{ Embryo response \% } & \multicolumn{4}{|c|}{ Shoot bud \% } & \multicolumn{4}{|c|}{ Plantlet \% } \\
\hline & control & $2000(\mathrm{ppm})$ & 4000 & (ppm) & control & $\begin{array}{l}2000 \\
(\mathrm{ppm})\end{array}$ & $\begin{array}{c}4000 \\
(\mathrm{ppm})\end{array}$ & Comb & control & $\begin{array}{c}2000 \\
(\mathrm{ppm})\end{array}$ & $\begin{array}{c}4000 \\
(\mathrm{ppm})\end{array}$ & Comb \\
\hline$\sigma^{2} \mathbf{g}$ & 108.20 & _ & & _- & 277.29 & 139.78 & 44.58 & 135.55 & 629.18 & 139.65 & 305.35 & 167.40 \\
\hline$\sigma^{2} L$ & - & - & & - & - & - & - & 32.85 & - & - & - & 108.16 \\
\hline$\sigma^{2} g \times L$ & - & - & & - & - & - & - & 1.66 & - & - & - & 190.66 \\
\hline$\sigma^{2} e$ & 27.174 & - & & - & 111.101 & 133.08 & 37.309 & 93.830 & 408.308 & 30.952 & 136.77 & 192.010 \\
\hline $\mathbf{h}_{\mathbf{b}} \%$ & 79.93 & - & & - & 67.17 & 51.23 & 54.44 & 51.37 & 60.64 & 81.86 & 69.06 & 25.43 \\
\hline C.V & 0.22 & - & & - & 0.26 & 0.28 & 0.16 & 0.26 & 0.50 & 0.28 & 0.48 & 0.50 \\
\hline
\end{tabular}

